ИЗВЕСТИЯ АКАДЕМИИ НАУК ЭСТОНСКОП ССР. ТОМ 23 ХИМИЯ * ГЕОЛОГИЯ. $1974, N_{2} 4$

\title{
РАСПРЕДЕЛЕНИЕ АУТИГЕННОГО КРЕМНЕЗЕМА В СИЛУРИЙКИХ ОТЛОЖЕНИЯХ ПРИБАЛТИКИ
}

В ходе литологического исследования силурийских пород Прибалтики в первую очередь привлекли к себе внимание наиболее яркие формы проявления аутигенного кремнезема - конкреции, окремнелые окаменелости и окремнелые породы (Юргенсон, 1958a, 1970). Последующие исследования показали его широкое распространение, хотя и с незначительным в большинстве случаев содержанием. В настоящей работе рассматривается распределение аутигенного кремнезема во всех типах силурийских отложений, а. также изучаются формы его проявления. Для выяснения роли аутигенного кремнезема в процессе осадконакопления и образования породы были установлены его соотношения со вмещающими породами и другими составляющими компонентами. Для этого проанализировано 600 образцов легких минералов алевритовой фракции $(0,1-0,01$ мм $)$ нерастворимого в $3,5 \%$-ной $\mathrm{HCl}$ остатка из 25 разрезов Прибалтики. Кроме содержания, установлены минералогический (100 оптических и 8 рентгенографических анализов) и химический состав (12 анализов) кремнезема.

В результате микроскопического исследования выяснилось, что около $60 \%$ проб аутигенного кремнезема представлено в виде микро- и скрытокристаллических зерен. Форма зерен различная. Интерес представляет небольшая часть зерен овальной или округлой формы (рис. $1, A)$. Сложены они из микрокристаллической стенки толщиной около 0,03 мм и микрозернистой Желтоватой внутренней части, заполненной глинистым материалом. Диаметр всего образования колеблется в пределах 0,15-0,35×0,04-0,20 мм. Происхождение таких зерен, по всей вероятности, органическое, хотя не исключено и микроконкреционное. До окончательного выяснения их сущности и для отличия их от других зерен они названы зооморфными.

В $30 \%$ исследованных зерен аутигенного кремнезема установлена сферолическая волокнистая микроструктура. И среди таких зерен можно выделить небольшую часть зооморфных (рис. 1,Б), отличающихся как внешним видом, так и внутренним строением от микрокристаллических зооморфных зерен. Размеры волокнистых зооморфных зерен не превышают 0,2 м.м.

До $7 \%$ зерен аутигенного кремнезема оказались стекловидными, угловатыми и шариковыми, изотропными зернами опала. Только $3 \%$ зерен представлены бипирамидальными кристаллами кварца. Особенно крупные кристаллы кварца были обнаружены внутри некоторых кремневых желваковидных конкреций (Юргенсон, 1958а), где размеры их достигают одного сантиметра.

По данным химических анализов аутигенный кремнезем конкреций 


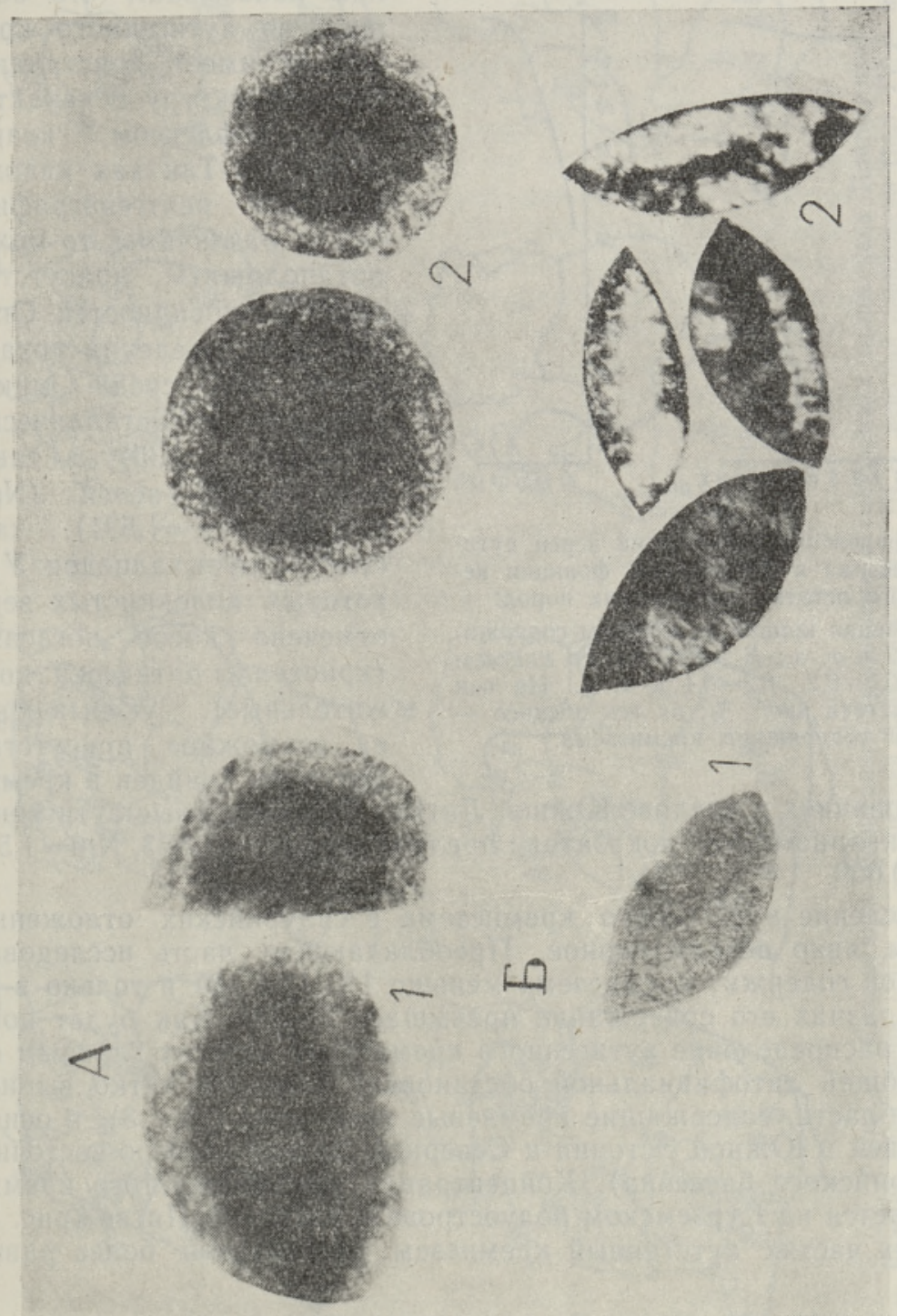

ڤั)

숭올

1

- $\dot{5}^{m} \frac{1}{x}$

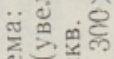

的

焉

$\frac{1}{2}=$

누는

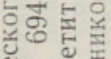

它茫

톤올 중

ง

일

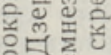

产的志

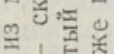

둥 운

…등

층

용 ㅃ.

도. 컹ㅇㅇ

世

त्ञ

ऽ。

敉

产到

응 =

잉 $\frac{10}{3}$

的要

15它式

૪

- त् तु

i 
содержит: $\mathrm{SiO}_{2}-93,0-97,3 \%, \mathrm{Fe}_{2} \mathrm{O}_{3}-0-2,4 \%, \mathrm{CaO}-0,4-3,0 \%$, $\mathrm{MgO}-0,2-2,6 \%$. Кальций и магний представлены главным образом в виде карбонатов, особенно во внешней части конкреций. Окись железа присутствует в виде пирита и гидрогематита.
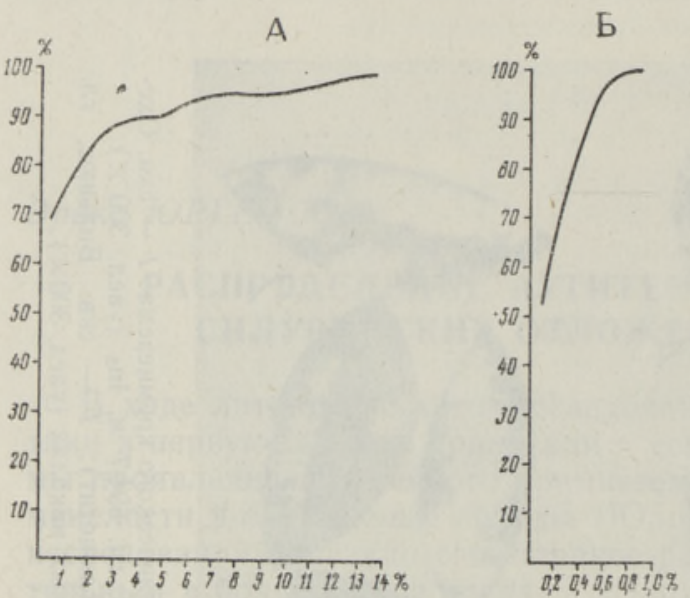

Рентгеноструктурный анализ показывает, что большинство аутигенного кремнезема имеет кристаллическую структуру с характерным рефлексом кварца $(3,343 \AA)$. Так как кварц и халцедон рентгенографически не различимы, то можно предположить присутствие обеих разновидностей. Оптические определения показывают, что среди микрои скрытокристаллических $(\mathrm{N}=1,539-1,535)$, а также волокнистых зерен $(\mathrm{Ng}=$ $=1,539$, $\mathrm{Nm}=1,531)$, чаще

Рис. 2. Распределение содержаний зерен аутигенного кремнезема в алевритовой фракции нерастворимого остатка силурийских пород:

$A-$ кумулятивная кривая по классам содержания $0-1,1-2$ и т. д.; Б - то же по классам содержания $0,0-0,2, \quad 0,2-0,4$ и т. д. На оси ординат - частота проб, \%; на оси абсцисс классы содержания кремнезема.

присутствует халцедон. У некоторых волокнистых зерен отмечено косое погасание (кристаллы оптически положительные), указывающее на возможное присутствие лютецита (найден в кремнистых образованиях в лудлове Южной Литвы). Идиоморфные аутигенные кристаллы кварца имеют показатели преломления $\mathrm{Ng}=1,553, \mathrm{Nm}=1,544$, $\mathrm{Ng}-\mathrm{Nm}=0,009$.

Распределение аутигенного кремнезема в силурийских отложениях Прибалтики явно неравномерное. Преобладающая часть исследованных образцов содержит кремнезема меньше $1 \%$ (рис. 2) и только в некоторых образцах его содержание превышает 2-3\%. Как будет показано ниже, распределение аутигенного кремнезема зависит главным образом от общей литофациальной обстановки. Наиболее четко вырисовываются области, содержащие кремневые конкреции (рис. 3), в основном в Средней и Южной Әстонии и Северной Латвии (северо-восточная часть силурийского бассейна). Концентрация мелкозернистого кремнезема отмечается на Курземском полуострове и в Южной Литве (рис. 3). В остальных частях аутигенный кремнезем распределен более равномерно.

Детальное изучение характера распространения показывает, что повышенное содержание микрокристаллического и волокнистого кремнезема приходится и на верхние слои ордовика в некоторых разрезах Южной Литвы (Вирбалис, Укмерге, Вильнюс). Его содержание в легкой части' алевритовой фракции нерастворимого остатка достигает местами до $60 \%$. Вмещающие породы представлены здесь известняками и доломитами (в разрезе Укмерге оолитовыми известняками).

Содержание аутигенного кремнезема в нижнелландоверийских отложениях сравнительно скромное (рис. $3_{\text {I }}$ ). Только в некоторых разрезах Средней Эстонии встречаются редкие небольшие конкреции. Основная 


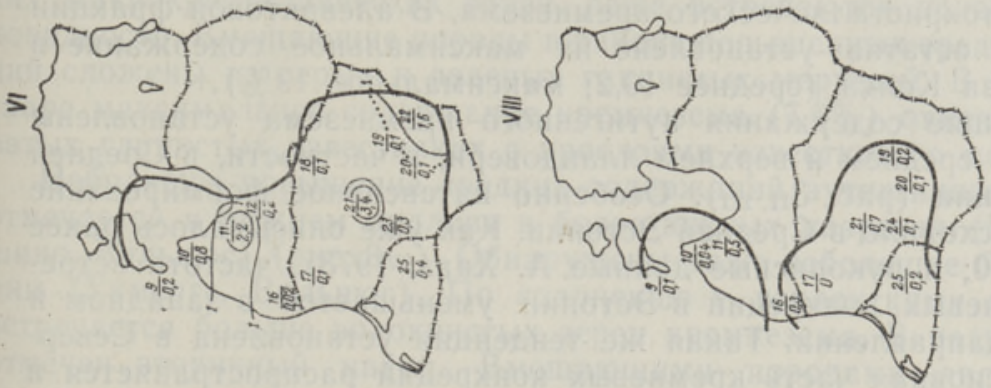

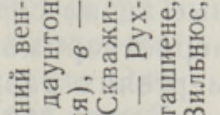

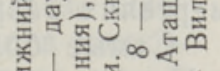

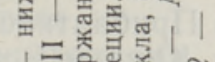

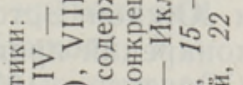

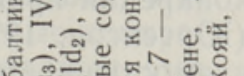

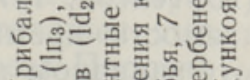
点=

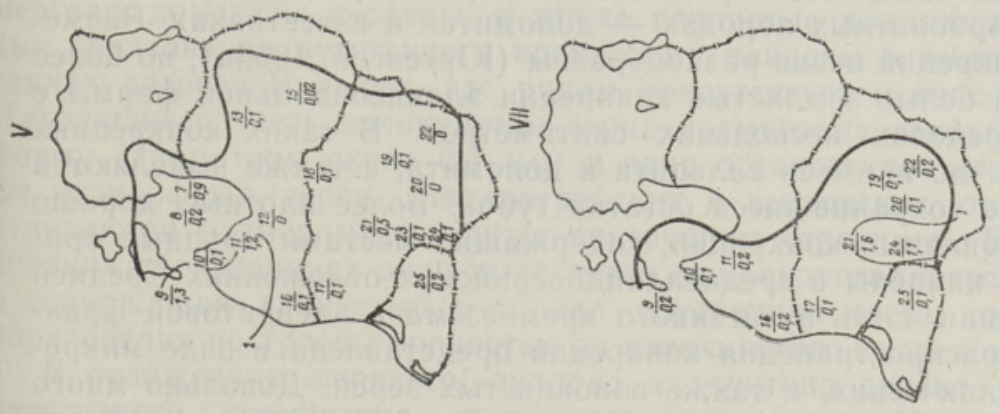
․ㅜ인 的



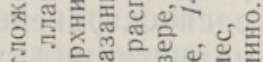

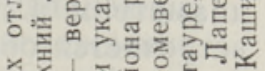

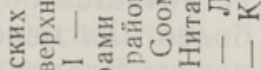

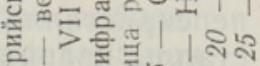

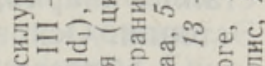

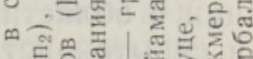
凹

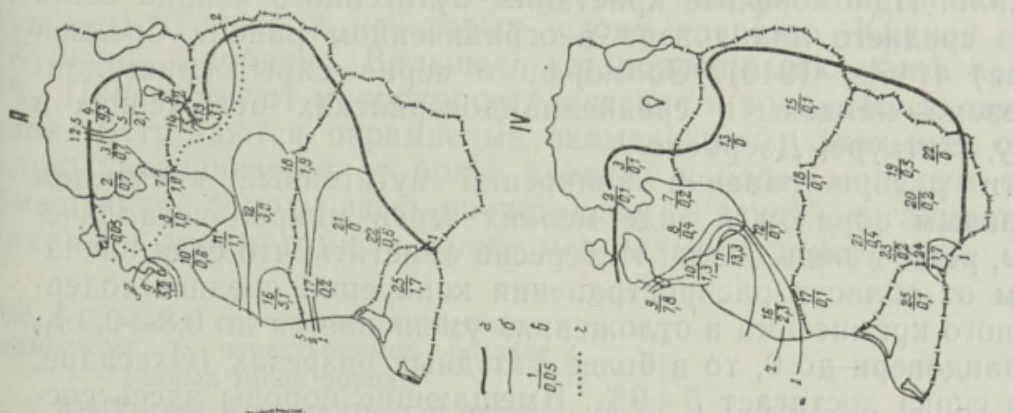

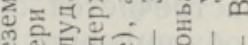

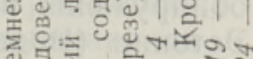



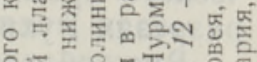

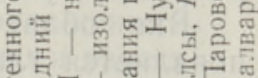

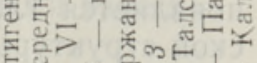
ब 1 ब.

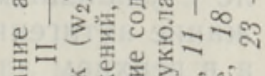

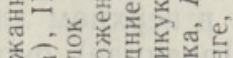

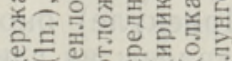

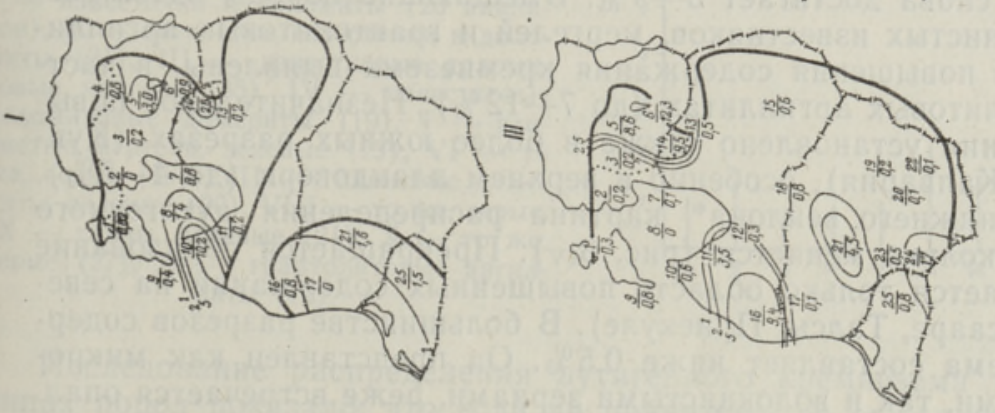
ธั

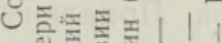
๓

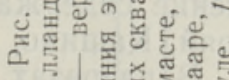

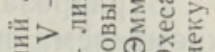

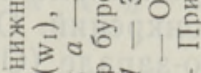
주인

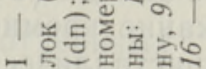


часть кремнезема в отложениях представлена в виде микрокристаллических зерен. В разрезах Рухну и Дзербене найдены округлые зооморфные зерна скрытокристаллического кремнезема. В алевритовой фракции нерастворимого остатка установлено их максимальное содержание в мергелях разреза Колка (среднее 10,2; максимальное 19\%).

Самые большие содержания аутигенного кремнезема установлены в Прибалтике в среднем и верхнем лландовери, в частности, в Средней и Южной Әстонии (рис. 3ІІ, ІІІ). Особенно интенсивное формирование конкреций пронсходило в Средней Эстонии. Как уже описывалось ранее (Юргенсон, 1970; и рукописные данные А. Хааз, 1973), частота встречаемости кремневых конкреций в Эстонии уменьшается в западном и юго-западном направлении. Такая же тенденция установлена в Северной Латвии. Основная часть кремневых конкреций распространяется в более чистых карбонатных породах - доломитах и известняках. Размеры и форма конкреций очень разнообразны (Юргенсон, 1958а), но более распространены белые землистые конкреции эллипсоидальной формы с диаметром в пределах нескольких сантиметров. В таких конкрециях встречается обычно примесь кальцита и доломита, а также выделяются более или менее сохранившиеся остатки губок. Более плотные, хорошо перекристаллизованные конкреции, содержащие местами крупные кристаллы кварца, найдены в среднелландоверийских отложениях Средней Эстонии. Основная часть аутигенного кремнезема в алевритовой фракции в области распространения конкреций представлена в виде микрои скрытокристаллических, а также волокнистых зерен. Довольно много встречается опала. Идиоморфные кристаллы аутигенного кварца были обнаружены из среднего лландовери в ограниченном районе Средней Әстонии (Водья) (Möls, 1940). Зооморфные зерна скрытокристаллического кремнезема найдены в среднелландоверийских отложениях в разрезах Рухну, Нитауре, Дзербене.

Вне области распространения конкреций аутигенный кремнезем появляется главным образом в виде мелких зерен микрокристаллической структуры, реже в виде опала. Интересно отметить, что если вначале с удалением от области распространения конкреций среднее содержание аутигенного кремнезема в отложениях уменьшается до $0,8-0,9 \%$, а в верхнем лландовери до 0, то в более западных разрезах (Охесааре, Приекуле) оно снова достигает 5-9\%. Вмещающие породы здесь составлены из глинистых известняков, мергелей и граптолитовых аргиллитов. Локальные повышения содержания кремнезема выявлены, в частности, в граптолитовых аргиллитах (до 7-12\%). Незначительное повышение содержания установлено также в более южных разрезах (Кункояй, Кашино, Калвария), особенно в верхнем лландовери (до $4-5 \%$ ).

В разрезах нижнего венлока* картина распределения аутигенного кремнезема несколько меняется (рис. 3IV). Прекращается образование конкреций. Остается только область повышенных содержаний на северо-западе (Охесааре, Талсы, Приекуле). В большинстве разрезов содержание кремнезема составляет ниже $0,5 \%$. Он представлен как микрокристаллическими, так и волокнистыми зернами, реже встречается опал. Зооморфные зерна кремнезема были найдены только в разрезе Охесааре. Характерными отложениями, содержащими аутигенный кремнезем, являются серые мергели и глины, местами зеленые глины.

В верхнем венлоке содержание аутигенного кремнезема повсеместно уменьшается (рис. 3v). Аналогично нижнему венлоку повышение

* Граница нижнего и верхнего венлока соответствует в данной работе границе яаниского и яагарахуского горизонтов в Эстонии. Таким же образом рассчитаны и объемы подъярусов. 
средних содержаний происходит в северо-западных разрезах (Охесааре, Талсы). Представлен аутигенный кремнезем в основном в виде мелких микрокристаллических зерен, реже встречаются волокнистые разновидности. Вмещающие породы в районе повышенных средних содержаний сложены из серых и зеленых глинистых мергелей. В разрезе Охесааре максимальное содержание кремнезема $(7,6 \%)$ отмечено в комковатых глинистых известняках с прослоями известкового мергеля.

Небольшое повышение средних содержаний аутигенного кремнезема отмечается в нижнем лудлове в более южных разрезах (Кункояй, Кашино, Вильнюс) (рис. 3vi). Обнаружены даже небольшие белые конкреции (Укмерге, Вильнюс). По сравнению с венлокскими отложениями встречается больше волокнистых зерен кремнезема. В разрезе Паровея отмечен вторичный кварц. Вмещающими породами являются серые мергели, домериты и глины, а также глинистые доломиты. Своеобразные образования аутигенного кремнезема найдены в нижнелудловских глинах разреза Вильнюс, где рядом присутствует и гипс и ангидрит. Находящиеся здесь волокнистые зерна кремнезема имеют удлиненную форму (диаметром около 0,4 мм) и явно органогенное происхождение. От зооморфных зерен лландоверийских и венлокских отложений они отличаются размерами, а также внутренним строением. Если в более древних образованиях явно выделяется микрокристаллическая внешняя и содержащая глинистый материал внутренняя части, то лудловские образования построены полностью из волокнистого халцедона (рис, $1, \overline{\text { ) }}$.

В отложениях верхнего лудлова и даунтона среднее содержание аутигенного кремнезема составляет повсеместно ниже $1 \%$ (рис. 3vп, vші). Только в некоторых слоях разрезов Южной Прибалтики (Кункояй, Вирбалис, Вильнюс) установлены локальные повышения до $2 \%$. Присутствуют микрокристаллические и волокнистые зерна, а также опал. Встречаются окремнелые окаменелости. Значение опала постепенно увеличивается от более древних к более молодым отложениям. Вмещающие породы здесь представлены в основном глинистыми известняками и доломитами, а также мергелями и домеритами.

Рис. 4. Средние содержания аутигенного кремнезема в нерастворимом остатке разных типов пород:

I - известняки и доломиты (20 анализов), II - глинистые известняки и доломиты (31), III - известковые доломитовые мергели (35), IV - известковые доломитовые домериты (19), V - глинистые мергели, зеленые (19), VI - то же, серые (19); VII - глинистые домериты, зеленые (20), VIII - то же, серые, IX - глины, зеленые (21), X - то же, серые (27), XI - граптолитовые аргиллиты (15).

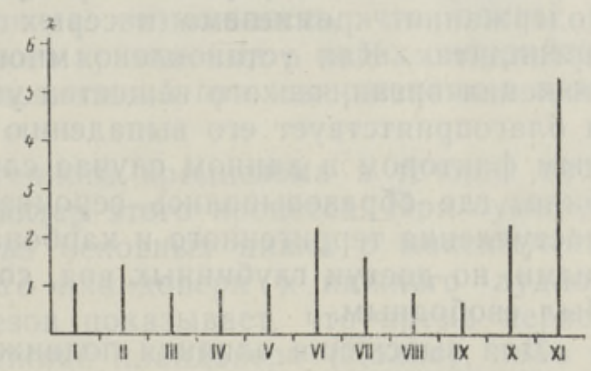

Исследование распределения аутигенного кремнезема в отдельных типах пород показало, что если не принимать во внимание конкреции, то средние содержания зернистого аутигенного кремнезема мало отличаются между собой. Более богатыми кремнеземом оказались серые глинистые мергели, серые глины и граптолитовые аргиллиты, в которых среднее содержание превышает $2 \%$ (рис. 4). Нам кажется, что на диагенетическое осаждение кремнезема влияет не столько соотношение карбонатов и терригенного материала, сколько присутствие органического вещества и общий гидродинамический режим среды. Исследование современного процесса осадконакопления показывает, что кремне- 


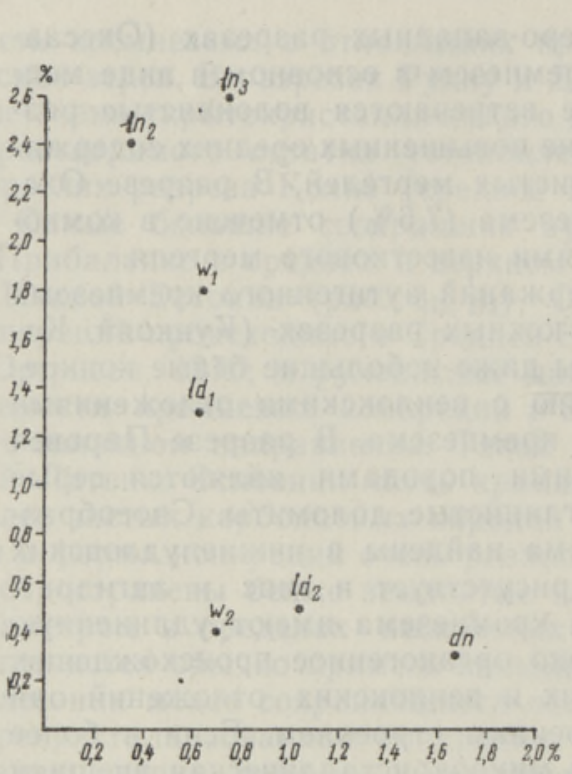

Рис. 5. Зависимость между средними содержаниями аутигенного кремнезема (на оси ординат) и аллотигенными тяжелыми минералами (на оси абсцисс). Количество анализов:

$\ln _{1}-50, \ln _{2}-91, \ln _{3}-79, \mathrm{w}_{1}-94$, $\mathrm{w}_{2}-84,1 \mathrm{~d}_{1}-124,1 \mathrm{~d}_{2}-57, \mathrm{dn}-100$.
A

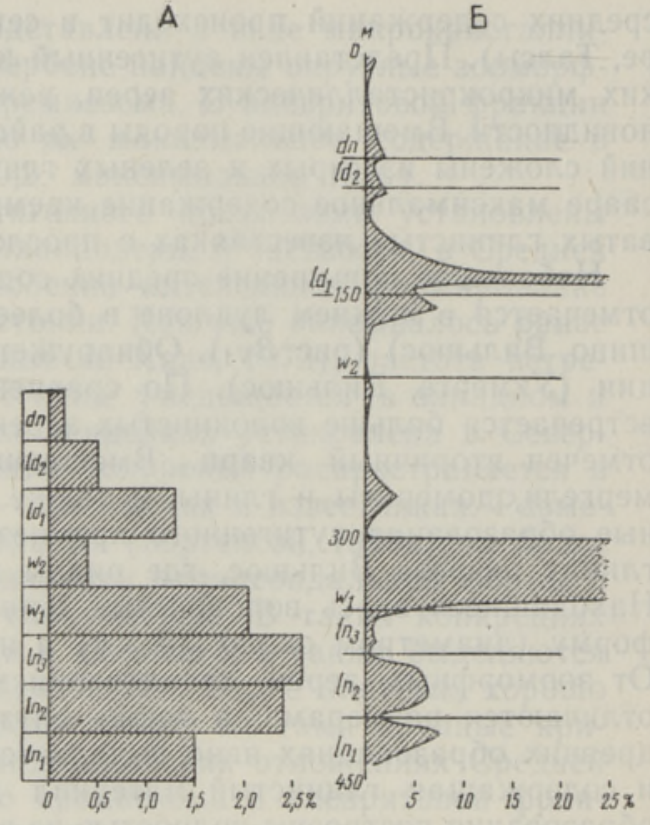

Рнс. 6. Распределение аутигенного кремнезема в разрезе силура Прибалтики: $A-$ средние содержания по подъярусам и ярусам, $\bar{B}$ - содержания в разрезе Охеcaape.

зем в морских и океанических водах находится в состоянии резкого недонасыщения. Его осаждение происходит либо непосредственным бногенным путем (кремневые скелеты организмов), либо под воздействием разложения органического вещества (Лисицын, 1966). Последний фактор надо, по-видимому, особенно учитывать при объяснении повышения содержания кремнезема в серых мергелях, глинах и граптолитовых аргиллитах. Қак установлено многими исследователями, процесс разложения органического вещества уменьшает растворимость кремнезема и благоприятствует его выпадению из поровых растворов. Благоприятным фактором в данном случае служила и относительно большая глубина, где образовывались сероцветные осадки. Подвижность воды и поступления терригенного и карбонатного материала были незначительными, но доступ глубинных вод, содержащих растворенный кремнезем, был свободным.

Для выяснения влияния подвижности воды на выпадение кремнезема была изучена связь между аутигенным кремнеземом и аллотигенными тяжелыми минералами (в целом), накопившимися в условиях активного стока с материка. Выясняется, что наибольшие средние содержания одного компонента соответствуют наименьшим содержаниям другого (рис. 5). Особенно хорошо это прослеживается в более западных разрезах, где дифференциация терригенного материала более полная.

С другой стороны отмечается, что более интенсивное, образование кремнезема, особенно в среднелландоверийских отложениях, совпадает с интенсивным образованием аутигенных минералов железа (пирит, гидрогематит), причем последние встречаются в отложениях как совместно, так и в виде включений в кремнистых образованиях. 
При прослеживании распределения аутигенного кремнезема в силурийском бассейне Прибалтики вырисовываются два основных района, в которых происходило более интенсивное его накопление. Первый из них располагался ближе к берегу, где осаждались известковые, местами и доломитовые илы (в среднем и верхнем лландовери на северовостоке, в нижнем лудлове на юго-востоке бассейна), а также присутствовали организмы с кремневыми скелетами. Рельеф дна был пологим. Источниками растворенного кремнезема служили терригенные минералы. Образовавшийся в ннжнем лудлове лютецит вместе с гипсом и ангидритом говорит о высокой щелочности среды, как это было установлено в разных палеозойских отложениях Северной Америки Л. Р. Фолком и Дж. С. Питтманом (Folk, Pittman, 1971).

Второй район более интенсивного накопления кремнезема распространялся ближе к центральной части бассейна. В малоподвижных, сравнительно глубоководных условиях в присутствии свободного $\mathrm{C}_{\text {op }}$ образовывались мелкие зерна разной формы. Возможно, что и здесь присутствовали какие-то кремневые организмы (зооморфные зерна!), характер которых пока не ясен. В более западных районах бассейна условия такого типа сохранились почти до даунтона.

Вопрос о влиянии вулканизма на аутигенное кремнеобразование в силуре Прибалтики остается пока открытым. Как уже отмечалось ранее (Юргенсон, 1958б, 1964), бесспорным доказательством в пользу такого влияния служит окремнение лландоверийских и венлокских отложений вблизи метабентонитовых прослоев в катагенезе, а также совпадение более интенсивных проявлений аутигенного кремнезема в ордовике и силуре с периодами более частого образования метабентонитов. Согласно исследованиям современных осадков (Лисицын и др., 1966), прямой связи между развитием вулканизма и кремнистыми осадками, образованными в основном организмами с кремневым скелетом, не существует. Их совмещение возможно лишь тогда, когда экологические и гидродинамические факторы в совокупности способствуют накоплению кремневых организмов вблизи районов вулканизма (Каледа, 1966). Таким образом, не исключена возможность, что одним из источников образования растворенного кремнезема в водах силурийского бассейна мог быть и материал, возникший при извержениях в грампианской геосинклинали.

Исследование накопления аутигенного кремнезема в течение всего силура показывает цикличный характер этого процесса. При суммировании всех данных выявляются два основных цикла с максимумами содержаний в отложениях верхнего лландовери и нижнего лудлова (рис. 6). Анализ отдельных разрезов показывает, что время первого максимума приходится либо на нижний лландовери (Колка), либо на средний лландовери (Нурме, Икла, Рухну), либо на верхний лландовери (Соомевере, Талсы, Приекуле, Дзербене, Кункояй). В разрезе Oхесааре самый крупный максимум отмечается в нижнем венлоке (рис. 6), причем небольшие максимумы появляются и в нижнем и среднем лландовери. Второй максимум в нижнем лудлове совпадает во всех разрезах. Общая интенсивность образования аутигенного кремнезема уменьшается к более молодым отложениям. Интересно отметить; что на границах более крупных стратиграфических единиц содержание аутигенного кремнезема уменышается. Обычно интенсивное накопление терригенного материала происходит здесь вследствие наступающей трансгрессии. Интенсивное накопление кремнезема более тяготеет к регрессивной части седиментационного цикла, о чем свидетельствует и упомянутая выше отрицательная связь с тяжелыми аллотигенными минералами 


\section{Л И ТЕ Р А Т У Р А}

Каледа Г. А. 1966. Основные черты эволюции кремнистого осадконакопления. В кн.: Геохимия кремнезема. М.

Л иси цын А. П. 1966. Основные закономерности распределения современных кремнистых осадков и их связь с климатической зональностью. В кн.: Геохимия кремнезема. $M$.

Лисицын А. П., Беляев Ю. Н., Богданов Ю. А., Богоявленский А. Н. 1966. Закономерности раопределения и формы кремния, взвешенного в водах Мирового океана. В кн.: Геохимия кремнезема. М.

Юргенсон Э.А. 1958a. О кремневых образованиях в ордовикских и силурийских жарбонатных породах Эстонской ССР. Тр. Ин-та геол. АН ЭССР, II.

Юргенсон Э. А. 19586. Метабентониты Эстонской ССР. Тр. Ин-та геол. АН ӘCCP, II.

Юргенсон Э. А. 1964. Силурийские метабентониты Эстонской ССР. В сб.: Литология палеозойоких отложений Эстонии. Таллин.

Юргенсон Э. А. 1970. Вторичные изменения силурийских отложений, В кн: Силур Эстонии. Таллин.

Folk L. R., Pittman J. S. 1971. Length-slow chalcedony: a new testament for vanished evaporites. J. Sediment. Petrol., 41, No. 4.

Möls E. 1940. Kvartsikristallid Vodja murrus. Eesti Loodus, 7, Nr. 4/5.
Ннститут геологии
Академии наук Эстонской ССР
Поступила

\section{Erika JORGENSON}

\section{AUTIGEENSE RÄNI LEVIK BALTI SILURI SETTEIS}

Siluri kivimite lahustumatu jäägi uurimine näitas, et peale juba varem uuritud ränikonkretsioonide ja ränistunud kivististe esineb autigeenset räni väikeste teradena peaaegu kōigis siluri kihtides (opaal, kaltsedon, kvarts). Sagedamini on tema sisaldus lahustumatu jäägi aleuriitse fraktsiooni kergete mineraalide hulgas alla $2 \%$ (joon. 2). Mitmesuguse kujuga mikrokristalliliste või kiuliste terade hulgas esineb ka omapäraseid zoomorfseid teri (joon. 1). Maksimaalset autigeense räni levikut võib märkida kesk- ja ülemländouveris, veidi suuremal hulgal ka alamlädlous (joon. 31-vmi; joon. 6). Suuremaid ränisisaldusi esineb peamiselt kolmes regioonis: 1) Kesk- ja LônaEestis ning Pōhja-Lätis, 2) Kuramaal ja 3) Kagu- ja Lōuna-Leedus. Autigeense räni tekkimine ei olene eriti karbonaatkivimite tüübist (joon. 4): tema teket on soodustanud räniorganismid (käsnade nōelad konkretsioonides), sissekantava terrigeense materjali kōrge porsumisaste, orgaanilise ainese lagunemine sügavamaveelistes mudades ja vulkaanilise tegevuse tagajärjel sissekantud ränirikka materjali lahustumine. Enamasti on autigeense räni teke toimunud settetsükli regressiivses osas. Selle üheks kinnituseks on autigeense räni sisalduse ja allotigeensete raskete mineraalide sisalduse negatiivne korrelatsioon setteis (joon. 5).

\section{Erika JORGENSON}

\section{DISTRIBUTION OF THE AUTHIGENIC SILICA IN THE EAST BALTIC SILURIAN DEPOSITS}

Investigation of the insoluble residue of Silurian rocks shows a wide distribution of authigenic silica in form of microcristalline and fibreous grains. Opal, chalcedony and quartz are present. Most frequently, the content of silica grains, among the light minerals in silt fraction of insoluble residue, does not exceed 2 per cent (Fig. 2). Problematic grains are found which may be of organic origin (Fig. 1). Maximum distribution of authigenic silica occurs in the deposits of the Middle and Upper Llandoverian and in the Lower Ludlovian (Fig. 3r-vin, Fig. 6). There are three regions where the formation of silica was most intensive - 1) Central and Southern Estonia and Northern Latvia, 2) the peninsula of Kurzeme, and 3) South-Eastern and Southern Lithuania. Following factors can be mentioned as favouring the formation of authigenic silica: 1) siliceous organisms (sponges), 2) inflow of terrigenous material 
with a high degree of maturity, 3) decomposition of organic matter in the deepseated sea muds (graptolite argillites), 4) decomposition of siliceous volcanic materiai (metabentonites). The formation of authigenic silica is not very closely related to the carbonate sedimentation (Fig. 4). A more intensive formation of silica took place throughout the regressive phase of the sedimentation cycle, as there exists a negative correlation between the content of authigenic silica and allothigenic heavy minerals accumulated mainly in conditions of a transgression (Fig. 5). 